should be offered instead. The possibility of immune deficiency should be considered in an infant with recurrent or opportunistic infections.

Despite the very small risk of vaccine associated polio oral poliomyelitis vaccine is one of the safest (and most effective) vaccines in use today. The risk to contacts can be minimised by giving advice to parents of recently immunised babies on the need for strict personal hygiene, particularly washing hands after changing nappies. ${ }^{9}$ Immunising parents (unless previously unimmunised) at the same time as their children is of no additional benefit as the risk of paralysis is similar for vaccine recipients and contacts. Strategies to reduce the risk of the vaccine associated disease even further while retaining the advantages of oral poliomyelitis vaccine are currently being explored - for example, the use of a combined inactivated-live vaccine schedule. ${ }^{14}$ If these strategies are properly implemented the prospects for eradication are good.

1 Global eradication of poliomyelitis by the year 2000. WHO Weekly Epidemiological Record 1988;63:161-2.

2 Begg NT, Chamberlain R, Roebuck M. Paralytic poliomyelitis in England and Wales 1970-84. Epidemiol Infect 1987;99:97-106.
White PMB, Green J. Prevalence of antibody to poliovirus in England and Wales. BMF 1986.293:1153-5.

4 Van Wezel AL, Hazendonk AG. Intratypic serodifferentiation of poliomyelitis strains by strain-specific antisera. Intervirology 1978;11:2-8

5 World Health Organisation. Manual for the virological investigation of poliomyelitis. Geneva: WHO, 1990

6 Evans DMA, Dunn G, Minor PD, Schild GC, Cann AJ, Stanway G, et al. A single nucleotide change in the $5^{\prime}$ non-coding region of the genome of the Sabin type 3 poliovaccine is associated with increased neurovirulence. Nature 1985;314:548-50.

7 Expanded programme on immunisation (EPI): poliomyelitis in 1986, 1987 and 1988. WHO Weekly Epidemiological Record 1989;64:273-80.

8 WHO Consultative Group. The relation between acute persisting spinal paralysis and poliomyelitis-results of a ten-year enquiry. Bull WHO paralysis and polit

9 Department of Health. Immunisation against infectious disease. London: HMSO, 1990.

10 Collingham KE, Pollock TM, Roebuck MO. Paralytic poliomyelitis in England and Wales 1976-77. Lancet 1978;i:976-7.

11 Hall SM, Glickman M. The British Paediatric Surveillance Unit. Arch Dis Child 1988;63:344-6.

12 Hovi T, Stervik M, Kinnuune E. Diagnosis of poliomyelitis by demonstration of intrathecal synthesis of neutralising antibodies. F Infect Dis 1986;153 998-9.

13 Kubli D, Steffen R, Schar M. Importation of poliomyelitis to industrialise nations between 1975 and 1984: evaluation and conclusions for vaccination recommendations. $B M \mathcal{F}$ 1987;295:169-71.

14 National Academy of Sciences Institute of Medicine. An evaluation of poliomyelitis vaccine policy options. Washington, DC: National Academy Press, 1988

\title{
Recruitment methods for screening programmes: trial of a new method within a regional osteoporosis study
}

\author{
M J Garton, D J Torgerson, C Donaldson, I T Russell, D M Reid
}

Department of

Rheumatology, City

Hospital, Aberdeen AB9 8AU

M J Garton, clinical research fellow

D M Reid, consultant

rheumatologist

Health Economics

Research Unit, University

of Aberdeen, Foresterhill,

Aberdeen AB9 2ZD

D J Torgerson, research

fellow

C Donaldson, deputy director

Health Services Research • Unit, University of

Aberdeen, Foresterhill,

Aberdeen AB9 2ZD

I T Russell, director

Correspondence to:

Dr Garton.

BMf 1992;305:82-4

\section{Abstract}

Objective-To estimate the response rates and operating costs of three recruitment methods within a regional osteoporosis screening programme.

Design-Randomised trial of three types of invitation letter: one offering fixed appointments with option to change time, one offering fixed appointments but requiring telephoned confirmation of intention to attend, and one inviting recipient to telephone to make an appointment.

Setting-Osteoporosis screening unit, Aberdeen.

Subjects-1200 women aged 45-49 years living within $32 \mathrm{~km}$ of Aberdeen and randomly selected from the community health index. 400 women were randomised to each appointment method.

Main outcome measures-Numbers attending for screening; default rate among women who confirmed appointments; social class of attenders; cost per appointment slot and per completed scan.

Results-299 (75\%), 277 (69\%), and 217 (54\%) women were scanned after fixed, confirmable, and open invitations respectively. Women who attended were given a questionnaire, and $694(87.5 \%)$ returned it. No significant differences were found in the social class of attenders among the three methods. Of the 514 women who made or confirmed appointments, 494 attended for a scan. Total costs per scan were $£ 25.00, £ 21.40$, and $£ 21.00$ for fixed, confirmable, and open invitations respectively.

Conclusions-The offer of a fixed appointment requiring telephoned confirmation has the potential to reduce the costs of scanning without exaggerating any social bias or significantly reducing response rates provided that empty appointments can be rebooked at short notice.

\section{Introduction}

The NHS operates large scale screening services for carcinoma of the breast and cervix and population screening for osteoporosis is being evaluated in several research centres. To be successful screening requires accurate identification and efficient persuasion of the target population.

Screening by invitation is usually more effective than either opportunistic screening ${ }^{1}$ or self referral, ${ }^{2}$ but which method of invitation best combines good response rates with low cost is uncertain. Only two basic methods of invitation have been reported: fixed appointments with provision to alter the appointment if required and open ended invitations. Government guidelines for breast cancer screening suggest that specific appointments are preferred. ${ }^{3}$ Many studies have assessed the performance of both methods individually, ${ }^{4-11}$ and in the few studies that have compared the two specific invitations consistently outperformed open ended invitations. ${ }^{12-14}$

Response rates to fixed invitations rarely exceed $80 \%$, and so material and human resources are wasted. We compared three different invitation methods for compliance and efficiency within a larger study of population based screening for future osteoporosis by dual energy $x$ ray absorptiometry. At present population screening for osteoporosis remains controversial, and this paper does not address this issue.

\section{Subjects and methods}

The study was approved by the local ethics committee and took place in 1991 at the osteoporosis screening unit, City Hospital, Aberdeen. A single Norland XR26 bone densitometer operated by one full time radiographer was used to scan up to 10 patients a day at the hip and lumbar spine; each scan took about 10 minutes and women were booked in at half hour intervals.

\section{RECRUITMENT}

We identified women aged 45-49 years living in 20 postcode sectors within $32 \mathrm{~km}$ of Aberdeen through the community health index. ${ }^{15} \mathrm{~A}$ proportionate stratified random sample of 1200 women $^{16}$ was randomly 
allocated to receive one of three trial invitation letters. The sample size was selected to allow the detection of a $10 \%$ difference in response rates between each pair of groups $(\alpha=0.05,1-\beta=0.8)$.

Individually addressed letters signed by the director of the unit (DMR) were posted with enclosed leaflets about osteoporosis and screening. The wording of the different types of invitations was similar. The first type of invitation (fixed) offered specific appointments. The second type (confirmable) was similar but also required subjects to intimate their intention to attend; failure to do so within 10 days risked loss of appointment. The third type of letter (open) invited the women to telephone to make an appointment. All invitations allowed for appointments to be changed by telephone.

\section{DATA COLLECTION}

All letters returned by post and all telephone calls in response to the letters were recorded. No reminders were sent.

Attenders were asked to complete a detailed lifestyle questionnaire. Social class was determined from the occupations of the patient's spouse, the patient, or her father by using the registrar general's classification ${ }^{17}$; a simple division was made into non-manual (I, II, and IIIa) and manual (IIIb, IV, and V) classes. The social class structure of the target population was estimated from 1981 census data. ${ }^{18}$

\section{DATA ANALYSIS}

We calculated response rates and slot coverage rates (defined as the number of patients scanned divided by the number of appointment slots reserved) for each invitation type and compared them by the $\chi^{2}$ test using a significance level of $5 \%$; corresponding confidence intervals were derived with the computer package CIA. ${ }^{19}$

We calculated the costs associated with each method of invitation, assuming a yearly maximum of 2250 scans. Capital costs of the bone densitometer $(£ 60000)$ and the Portakabin ( $£ 15230)$ were discounted at $6 \%$ a year to produce annualised charges over their expected working lifetimes of six and 20 years respectively. Fixed costs were defined as those expenses incurred whether a scan was performed or not and variable costs as those added only if a scan were successfully completed. The total cost per scan was then estimated as (fixed cost per slot/slot coverage rate)+variable cost per scan). Confidence intervals for the cost per scan were obtained by substituting the upper and lower

TABLE I - Response rates and slot coverage rates ${ }^{\star}$ by type of invitation for osteoporosis screening

\begin{tabular}{|c|c|c|c|}
\hline & \multicolumn{3}{|c|}{ Invitation type } \\
\hline & Fixed & Confirmable & Open \\
\hline No invited & 400 & 400 & 400 \\
\hline No scanned & 299 & 277 & 217 \\
\hline \multirow{3}{*}{$\begin{array}{l}\text { Response rate ( } 95 \% \text { confidence } \\
\text { interval) }(\%) \\
\text { No of slots reserved } \\
\text { Slot coverage rate ( } 95 \% \text { confidence } \\
\text { interval })(\%)\end{array}$} & $75(71$ to 79 & 9) 69 (65 to 74$)$ & $54(49$ to 59$)$ \\
\hline & 373 & 292 & 222 \\
\hline & 80 (76 to 84 & 4) 95 (92 to 97$)$ & $98(95$ to 99$)$ \\
\hline
\end{tabular}

TABLE II -Comparison of response rates and slot coverage rates for three different methods of invitation for osteoporosis screening

\begin{tabular}{|c|c|c|c|c|c|c|}
\hline & \multicolumn{3}{|c|}{ Response rate } & \multicolumn{3}{|c|}{ Slot coverage rate } \\
\hline & $\begin{array}{c}\text { Difference } \\
(95 \% \\
\text { confidence } \\
\text { interval })\end{array}$ & $\begin{array}{c}\text { Uncorrected } \\
\chi^{2}\end{array}$ & $\mathrm{p}$ Value & $\begin{array}{c}\text { Difference } \\
(95 \% \\
\text { confidence } \\
\text { interval })\end{array}$ & $\begin{array}{c}\text { Uncorrected } \\
\chi^{2}\end{array}$ & $\mathrm{p}$ Value \\
\hline Fixed $v$ confirmable & $6(-1$ to 12$)$ & $3 \cdot 0$ & 0.083 & $15(10$ to 20$)$ & 30.5 & $<0.0001$ \\
\hline Fixed $v$ open & 21 (14 to 27$)$ & $36 \cdot 7$ & $<0.0001$ & $18(13$ to 22$)$ & $37 \cdot 4$ & $<0.0001$ \\
\hline Confirmable $v$ open & 15 (8 to 22$)$ & $19 \cdot 05$ & $<0.0001$ & $3(-0.3$ to 6$)$ & $2 \cdot 8$ & 0.094 \\
\hline
\end{tabular}

TABLE III - Estimated costs (£) of providing and filling 2250 scanning slots a year by type of invitation

\begin{tabular}{lrrr}
\hline & \multicolumn{3}{c}{ Invitation type } \\
\cline { 2 - 4 } Item & Fixed & Confirmable & Open \\
\hline Fixed cost: & & & \\
$\quad$ Scanner, Portakabin, light, & & & \\
$\quad$ furnishings & 20000 & 20000 & 20000 \\
Radiographer's salary & 18400 & 18400 & 18400 \\
Secretary's salary & 4910 & 5390 & 5500 \\
Postage & 382 & 382 & 695 \\
Total & 43700 & 44200 & 44600 \\
Fixed cost per slot & $19 \cdot 40$ & $19 \cdot 60$ & $19 \cdot 80$ \\
Variable cost per scan & $0 \cdot 74$ & $0 \cdot 74$ & $0 \cdot 74$ \\
& & &
\end{tabular}

confidence limits of the slot coverage rate in the calculation.

\section{Results}

Twelve hundred women were randomly assigned to the three methods of invitation. Twenty six $(2 \cdot 2 \%)$ of the letters were returned marked unknown at the given address. Table I shows the response rates and slot coverage rates for each method. The response rate for fixed invitations was $75 \%$ and for confirmable invitations $69 \%$; both rates were significantly better than that for open invitations $(54 \%, \mathrm{p}<0.0001)$. Although a proportion of non-attenders telephoned to cancel their fixed appointments in time for them to be reallocated, slot coverage rates were significantly $(p<0.0001)$ lower for fixed appointments (80\%) than for the other two methods of invitation ( $95 \%$ for confirmable and $98 \%$ for open invitations). Table II analyses the differences in response and slot coverage rates among the three types of invitation.

The social class structure of the $694(87 \cdot 5 \%)$ attenders who completed the questionnaire was not significantly different among invitation types; the percentages of non-manual respondents within the three groups were $63 \%$ (95\% confidence interval $57 \%$ to $69 \%)$ for fixed invitations, $68 \%(62 \%$ to $74 \%)$ for confirmable invitations, and $64 \%(57 \%$ to $71 \%)$ for open invitations. The 1981 census suggested that about two thirds of the female population of working age belonged to the non-manual social classes.

The fixed costs of each appointment slot were estimated as $£ 19.40, £ 19.60$, and $£ 19.80$ for fixed, confirmable, and open invitations respectively (table III), reflecting differences in secretarial time needed by each method and in postage costs implied by different response rates. The small variable cost of each scan was uniform across methods of invitation. The total cost per scan was $£ 25.00$ ( $£ 23.80$ to $£ 26.30$ ) for fixed invitations, $£ 21.40$ ( $£ 21.00$ to $£ 22.10$ ) for confirmable invitations and $£ 21.00$ ( $£ 20.70$ to $£ 21.60$ ) for open invitations; the higher cost of fixed invitations reflects the lower slot coverage rates.

\section{Discussion}

Our results confirm the results of previous studies that women respond better to fixed rather than open invitations. ${ }^{12-14}$ The introduction of a requirement to confirm a fixed appointment was associated with an insignificant reduction in the response rate, but the response rate for confirmable invitations was still considerably higher than that achieved with the open invitation. Open invitations extend screening opportunities to more individuals and offer maximum flexibility and cost efficiency but at the expense of compliance.

One quarter of women who received fixed invitations did not attend, and most of these appointment slots were unusable. However, of the 514 women who confirmed or made an appointment in response to a 
confirmable or open invitation, only $20(4 \%)$ defaulted. This differential wastage made fixed invitations nearly $20 \%$ more expensive than confirmable or open invitations. As screening services expand such costings will become more relevant. We know of no previous published work that estimates the cost of screening by allowing for differential response rates.

Bone density screening takes nearly 30 minutes and therefore requires scheduled appointments; late attenders are rare but disruptive. Deliberate overbooking would cause lengthy queues, which might be poorly tolerated by both patients and health authorities.

We detected no significant difference in social class among those who attended for a scan in response to the three methods of invitation and returned the postal questionnaire. As the social class of attenders was similar to that of the target population none of the invitation methods seemed to introduce a social class bias.

In conclusion, letters offering fixed appointments that require confirmation seem to combine acceptable response rates and efficient use of resources provided that unconfirmed appointments can be reassigned at short notice. A mixed strategy offering an open appointment as an initial invitation and a fixed appointment requiring telephoned confirmation as a reminder, might ensure the best use of human and materia resources while achieving an acceptable response rate. This hypothesis should be tested in a controlled study.

We thank Dr Susan McPhee, Professor Elizabeth Russell, the staff of the Grampian Health Board Medical Computing Centre, Mr Arthur Fernley of Grampian Regional Council, and an anonymous statistical referee. MJG and DJT were funded by a grant from the Wolfson Foundation. CD and ITR were supported by the chief scientist office of the Scottish Office Home and Health Department. DMR thanks the
Arthritis and Rheumatism Council for continued support. The views expressed here are not necessarily those of the funding bodies.

1 Pierce MS, Lundy S, Palanisamy A, Winning S, King J. Prospective randomised controlled trial of mats of call and recall for cervica cytology screening. BMF 1989;299:160-2.

2 Turnbull D, Irwig L, Adelson P. A randomised trial of invitations to attend for screening mammography. Australian fournal of Public Health 1991;15:33-6.

3 Department of Health Advisory Committee. Consolidated guidance on breast cancer screening. Oxford: Screening Publications, 1990:7.

4 Houghton BA. Response to cervical screening, a survey of tested and untested women in one Buckinghamshire practice. Medical Officer 1968;120:334-7.

5 George WD, Gleave EN, England PC, Wilson MC, Sellwood RA, Asbury D, et al. Screening for breast cancer. BMf 1976;ii:858-60.

6 Hobbs P, Smith A, George WD, Sellwood RA. Acceptors and rejectors of an invitation to undergo breast screening compared with those who referred themselves. I Epidemiol Community Health 1980;34: 19-22.

7 Editorial Committee of the Cardiff Cervical Cytology Study. The Cardiff cervical cytology study; enumeration and definition of population and initial

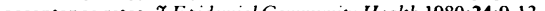

8 Ridsdale LL. Cervical screening in general practice: call and recall. $\mathcal{J} R$ Coll Gen Pract 1987:37:257-9.

9 Spenser JT. A survey of cervical smear screening in general practice. Practitioner 1967:198:274-80.

10 Robertso' AJ, Reid GS, Stoker CA, Bisset C, Waugh N, Fenton I, et al. Evaluation of a call programme for cervical cytology screening in women aged 50-60 years. $B M \mathcal{F} 1989 ; 299: 163-6$.

11 Hobbs P, Kay C, Friedman EHI, St Leger AS, Lambert C, Boggis CRM, et al. Response by women aged 65-79 to invitation for screening for breast cancer by mammography: a pilot study. BMF 1990;301:1314-6.

12 Wilson A, Leeming A. Cervical cytology screening: a comparison of two call systems. BMf 1987;295:181-2.

13 Williams EMI, Vessey MP. Randomised trial of two strategies offering women mobile screening for breast cancer. $B M \mathcal{F} 1989 ; 299: 158-9$.

14 Irwig L, Turnbull D, McMurchie $M$. A randomised trial of genera practitioner-written invitations to encourage attendance at screening mammography. Community Health Stud 1990;14:357-64.

15 Roworth MA. Jones IG. The community health index-How accurate is it? Community Med 1988;10:327-30.

16 Moser CA, Kalton G. Survey methods in social investigation. Aldershot: Gower, 1971:85-90.

17 Office of Population Censuses and Surveys. Classification of occupations. London: HMSO, 1980.

18 General Register Office. Population census small area statistics. Edinburgh General Register Office, 1981

19 Gardner MJ, Altman DG. Statistics with confidence. London: British Medica Journal, 1990:28-33.

(Accepted 6 May 1992)

\title{
Mild and moderate dyskaryosis: can women be selected for colposcopy on the basis of social criteria?
}

Harris Birthright Research Centre, Aberdeen Royal Infirmary, Foresterhill, Aberdeen AB9 2ZB

David J Anderson, research fellow

Grainne M Flannelly, research fellow

Henry C Kitchener, consultant gynaecologist

reter M Fisher, consultant gynaecologist

Evelyn M Mann, consultant cytopathologist

Marion K Campbell, medical statistician

Allan Templeton, professor of obstetrics and gynaecology

Correspondence to: Dr Kitchener.

BMF 1992;305:84-7

\author{
David J Anderson, Grainne M Flannelly, Henry C Kitchener, Peter M Fisher, Evelyn M Mann, \\ Marion K Campbell, Allan Templeton
}

\section{Abstract}

Objective-To describe the distribution of cervical intraepithelial neoplasia grades among women with mild and moderate dyskaryosis after a single cervical smear and to determine whether social criteria could help identify women who are at increased risk of grade II or III disease.

Design-Cross sectional analysis within a randomised prospective study. Subjects had a repeat smear, a colposcopic examination, and an excision biopsy of the transformation zone. In addition, women were asked to complete a social questionnaire.

Setting-Colposcopy clinic, Aberdeen.

Subjects-228 women with a single smear test showing mild or moderate dyskaryosis.

Main outcome measures-Histology, age, sexual and contraceptive history, cigarette smoking.

Results-159 (70\%) women had cervical intraepithelial neoplasia grades II or III. Among current smokers the prevalence of grade II and III disease was higher in women who smoked $\geqslant 20$ cigarettes a day $(84 \%)$ than among those who smoked less $(66 \%$; $\mathbf{p}<0.04)$. Women with more than one sexual partner also had a higher prevalence $(75 \%)$ than women with only one partner $(50 \% ; p=0 \cdot 0028)$. Use of oral contraceptives and younger age were not significantly associated. The prevalence of grade II or III disease was up to $66 \%$ in the lower risk groups.

Conclusions-Because of the high prevalence of cervical intraepithelial neoplasia grades II and III in both the high and the low risk groups social factors are not useful for selecting women with mild or moderate dyskaryosis for either early referral to colposcopy or cytological surveillance.

\section{Introduction}

It is generally agreed that women with severe dyskaryosis require colposcopy and cervical biopsy No clear consensus exists, however, on the managemen of mild and moderate dyskaryosis, which are detected 10 times more commonly than severe dyskaryosis. Two contrasting policies exist. The more conservative approach, cytological surveillance with referral to colposcopy only if the abnormality persists over 12-18 months, is based on the belief that a significan proportion of these cytological abnormalities revert to normal with time.

Cervical smears, however, often underestimate the severity of the underlying cervical lesions, with $15-50 \%$ of women with mild and moderate dyskaryosis having 